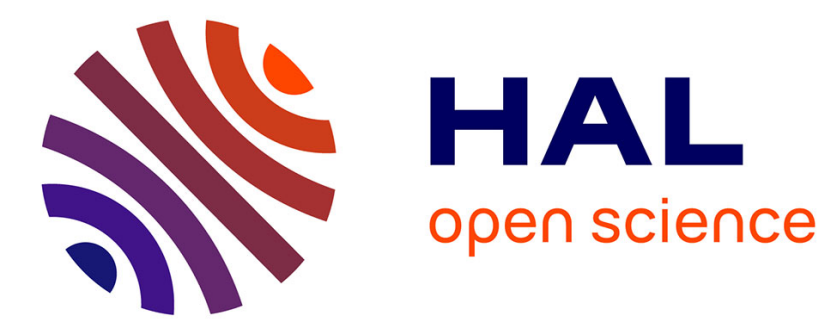

\title{
Autophagy as a mediator of chemotherapy-induced cell death in cancer
}

\author{
Annick Notte, Lionel Leclere, Carine Michiels
}

\section{To cite this version:}

Annick Notte, Lionel Leclere, Carine Michiels. Autophagy as a mediator of chemotherapy-induced cell death in cancer. Biochemical Pharmacology, 2011, 82 (5), pp.427. 10.1016/j.bcp.2011.06.015 . hal-00721647

\section{HAL Id: hal-00721647 \\ https://hal.science/hal-00721647}

Submitted on 29 Jul 2012

HAL is a multi-disciplinary open access archive for the deposit and dissemination of scientific research documents, whether they are published or not. The documents may come from teaching and research institutions in France or abroad, or from public or private research centers.
L'archive ouverte pluridisciplinaire HAL, est destinée au dépôt et à la diffusion de documents scientifiques de niveau recherche, publiés ou non, émanant des établissements d'enseignement et de recherche français ou étrangers, des laboratoires publics ou privés. 


\section{Accepted Manuscript}

Title: Autophagy as a mediator of chemotherapy-induced cell death in cancer

Authors: Annick Notte, Lionel Leclere, Carine Michiels

PII: $\quad$ S0006-2952(11)00380-7

DOI: $\quad$ doi:10.1016/j.bcp.2011.06.015

Reference: $\quad$ BCP 10939

To appear in: $\quad B C P$

Received date: $\quad 28-4-2011$

Revised date: $\quad 8-6-2011$

Accepted date: $\quad$ 8-6-2011

Please cite this article as: Notte A, Leclere L, Michiels C, Autophagy as a mediator of chemotherapy-induced cell death in cancer, Biochemical Pharmacology (2010), doi:10.1016/j.bcp.2011.06.015

This is a PDF file of an unedited manuscript that has been accepted for publication. As a service to our customers we are providing this early version of the manuscript. The manuscript will undergo copyediting, typesetting, and review of the resulting proof before it is published in its final form. Please note that during the production process errors may be discovered which could affect the content, and all legal disclaimers that apply to the journal pertain. 


\section{Autophagy as a mediator of chemotherapy-induced cell death in cancer}

Annick NOTTE, Lionel LECLERE, Carine MICHIELS*

URBC - NARILIS, University of Namur-FUNDP, Belgium

* Corresponding author. URBC, 61 rue de Bruxelles, University of Namur, 5000 Namur, Belgium. Tel : 32-81-724131, Fax : 32-81-724135, Email : carine.michiels@,fundp.ac.be

List of non-standard abbreviations: AMPK, AMP-dependent kinase ; Atg, autophagy-related gene ; DAMP, damage-associated molecular pattern molecules ; DAPK1, Death-associated protein kinase 1 ; ER, endoplasmic reticulum ; HDAC, histone deacetylase ; HIF-1, hypoxiainducible factor-1 ; HMGB1, high-mobility group box 1 ; mTOR, mammalian target of rapamycin ; PTEN, phosphatase and tensin homolog ; RAGE, receptor for advanced glycation endproducts ; ROS, reactive oxygen species ; TSC2, tuberous sclerosis protein 2 ; ULK, Unc151-like kinase ; UVRAG, ultraviolet radiation resistance associated gene 


\begin{abstract}
Since the 1940's, chemotherapy has been the treatment of choice for metastatic disease. Chemotherapeutic agents target proliferating cells, inducing cell death. For most of the history of chemotherapy, apoptosis was thought to be the only mechanism of drug-induced cell death. More recently, a second type of cell death pathway has emerged: autophagy, also called programmed type II cell death. Autophagy is a tightly-regulated process by which selected components of a cell are degraded. It primarily functions as a cell survival adaptive mechanism during stress conditions. However, persistent stress can also promote extensive autophagy, leading to cell death, hence its name. Alterations in the autophagy pathway have been described in cancer cells that suggest a tumor-suppressive function in early tumorigenesis, but a tumor-promoting function in established tumors. Moreover, accumulating data indicate a role for autophagy in chemotherapy-induced cancer cell death. Here, we discuss some of the evidence showing autophagy-dependent cell death induced by anti-neoplastic agents in different cancer models. On the other hand, in some other examples, autophagy dampens treatment efficacy, hence providing a therapeutic target to enhance cancer cell killing. In this paper, we propose a putative mechanism that could reconcile these two opposite observations.
\end{abstract}


In the unremitting fight against cancer, chemotherapies are one of the major tools that oncologists used to treat and cure patients, especially if a metastatic disease is diagnosed. Nitrogen mustards and antifolate agents were the first molecules to be used before the emergence of DNA-damaging agents and microtubule targeting drugs. Targeted therapy, based on specific alterations of cancer cells, is the next frontier in chemotherapy, [1-3]. However, the main objective of all of these approaches is to kill cancer cells.

For years, apoptosis was thought to be the principal mechanism by which chemotherapeutic agents kill cells. Apoptosis is a programmed cell death highly conserved that regulates the tissue homeostasis and/or eliminate damaged and infected cells. Two major apoptotic pathways exist: the extrinsic pathway mediated by death receptors and the intrinsic pathway mediated by mitochondria. These apoptotic signaling pathways lead to an important event: the activation of caspases, cysteine proteases that cleave different substrates eventually leading in cell dismantling.

Accumulating evidence now shows that anticancer agents also elicit other forms of nonapoptotic cell death including necrosis, mitotic catastrophe, autophagy and senescence [4-6]. Furthermore, a continuum exists between apoptosis and necrosis, depending, for example, on the concentration of the chemotherapy agent that the cancer cells are exposed to. Necrosis has been viewed as a form of accidental cell death brought by injury. Recent findings have suggested that some forms of necrosis are programmed; this process has been called necroptosis. In addition, autophagic and apoptotic features can be observed in the very same cell. Altogether, this leads to a complex wiring of cell death and survival networks that finally tilts cell fate towards death or life. The purpose of this review is to focus on the role of autophagy in anticancer agent-induced cell death.

\section{Autophagy: an introduction}


Autophagy is a self-degradative process that enables cells to cope with stresses such as nutrient deprivation, ER stress, pathogen infection or hypoxia. Autophagy is thus generally considered to be a survival mechanism. On the other hand, when the severity or the duration of the stress is too long, or in apoptotic-deficient cells, autophagy may participate in cell death. Therefore, it has been called type II programmed cell death (type I being apoptosis itself). The role of autophagy in cell demise was first proposed because a large number of autophagic vacuoles have been observed in dying cells from various animal species. This was thought to mainly occur during the developmental program (e.g. in salivary glands in Drosophila) or during homeostatic processes (e.g. during organ involution). More recent data have demonstrated autophagic features in cells treated with chemotherapeutic agents (see below). The question, "Is autophagy an innocent bystander, a direct cell death execution pathway, a defense mechanism that ultimately fails in its mission to preserve cell viability and/or a garbage disposal mechanism that cleans up remnants of a cell already committed to die" [7] still needs clarification. All may be true according to the circumstances.

There are three types of autophagy, all of which promote degradation of cytosolic components but differ in their mechanisms and functions: micro-autophagy, chaperone-mediated autophagy and (macro)-autophagy, which is the one considered in this review. Autophagy delivers portions of the cytosol, possibly including organelle(s), to the lysosome via its inclusion in a double membrane vesicle. The fusion of this vesicle with the lysosome permits the hydrolysis of its contents by the lysosomal acidic hydrolases. Permeases and transporters then export amino acids and other biomolecules into the cytosol where they can be reused for cell metabolism and synthesis. Through this process, autophagy provides building blocks in the event of nutrient deprivation and helps cells to sustain stresses. A specific form of macroautophagy is mitophagy, a process by which damaged mitochondria are degraded. 
Mechanisms inducing mitophagy involve the PTEN-induced putative kinase protein 1 (PINK1) and the E3 ubiquitin ligase, parkin.

Autophagy is a highly regulated process consisting of induction, cargo selection and recognition and vesicle formation, which produces the autophagosome that then fuses with a lysosome. Several signaling pathways that initiate autophagy converge at one serine/threonine protein kinase, mTOR (mammalian Target Of Rapamycin). The energy sensor AMPK (AMPdependent Kinase) is such an example. mTOR negatively regulates Atg1 (AuTophagy related Gene 1) or its mammalian homologs, ULK-1 and -2 (Unc-151-like kinase) in nutrient rich conditions, thus inhibiting autophagy [8]. Different sets of Atg proteins comprise the core of the autophagy machinery and are then involved in the next successive steps $[9,10]$. Of note is the role played by Beclin-1, a member of the Bcl-2 family. Beclin-1 is the mammalian homolog of the yeast Atg6 gene. When released from Bcl-2 at the level of the endoplasmic reticulum, Beclin-1 associates with the class III phosphatidylinositol 3-kinase Vps34, UVRAG (ultraviolet radiation resistance associated gene), and other partners that are required, in addition to the ULKs, for autophagy vesicle nucleation $[11,12]$. The next step in autophagophore elongation requires two ubiquitin-like systems: the first aims to conjugate Atg5 to ubiquitin-like Atg12 via the E1- and E2-like activities of Atg7 and Atg10, respectively. Atg5-Atg12 conjugates oligomerize and localize at the outer membrane of the expending membrane. The second system links Atg8 (also called LC3) that has been cleaved by Atg4 to phosphatidylethanolamine, which leads to LC3-II isoform. LC3-II is then recruited both at the inner and the outer membranes of the growing vesicle. Both complexes are required for membrane elongation and fusion leading to a closed vesicle. The completion of the autophagosome is followed by its fusion with a lysosome [8].

\section{$\underline{2 . \text { Role of autophagy in cancer }}$}


Alterations in the autophagy pathway in cancer cells raised a paradox because autophagy functions as a tumor suppressive mechanism, but is also used by cancer cells for cytoprotection to cope with their hostile microenvironment [13-15]. This dual role of autophagy in tumor development is illustrated by the fact that colorectal cancer patients with extensive over- or underexpression of Beclin-1 have a much poorer overall survival [16].

\subsection{Tumor suppressive functions of autophagy}

The first evidence that autophagy is tumor suppressive came from the observation that Beclin1 haplodeficient mice suffered from a high incidence of spontaneous tumors [17]. Beclin-1 down-regulation is also required for malignant transformation induced by oncogenic ras [18]. Furthermore, its expression is frequently decreased in human breast cancers [19] as well as in melanomas [20]. Both genetic and epigenetic silencing of the Beclin-1 gene has been shown in human breast tumors [21]. Combined decreased expression of Beclin-1 and LC-3 is also observed in human glioblastomas [22]. Alteration in other autophagy-involved genes has also been reported in different tumor types: this has been observed for Atg5 in a natural killerspecific leukemia [23], for UVRAG in colorectal and gastric carcinomas [24, 25], for Atg4C in $\mathrm{KO}$ mice that developed fibrosarcomas induced by methylcholanthrene [26] and for Bif-1 in human pancreatic ductal adenocarcinoma [27]. It has also to be mentioned that hyperactivation of the Akt pathway is observed in numerous cancer types, which positively regulates cell proliferation and survival while inhibiting autophagy through the activation of mTOR. Activating mutations of mTOR have recently been discovered in tumors that would also result in autophagy downregulation [28].

At least three mechanisms have been proposed to explain the tumor-suppressive function of autophagy. The first one is that autophagy eliminates damaged organelles that may produce high amounts of ROS (reactive oxygen species) and hence limits chromosomal instability 
[29]. Another consequence of autophagy is the elimination of p62, preventing the signal transduction adaptor function of p62 in pathways critical for oncogenesis [30]. A third mechanism would be to prevent cell necrosis in response to metabolic stress. Indeed, inflammatory cells infiltrate tumors in necrotic areas that then favor tumor growth [31]. Taken together, these observations suggest that basal autophagy is protective against cell transformation, i.e. in the early phase of tumorigenesis.

\subsection{Tumor promoting properties of autophagy}

Later, as tumors grow, cancer cells may need autophagy to survive their nutrient-limited and low-oxygen microenvironment, especially in the inner region of the tumor that is poorly vascularized. This ability to cope with stress is also useful to cancer cells that disseminate and metastasize [32]. Indeed, cell detachment from the extracellular matrix initiates a form of cell death that is called anoikis. Tumor cells must overcome anoikis in order to survive the invasion of blood fluid, and autophagy is one way of doing this [33]. This has been demonstrated using breast cancer cells in vitro [34]. Data obtained from patients with colorectal adenocarcinoma indeed showed a correlation between high LC3 accumulation with metastasis and poor prognosis [35]. The precise function of detachment-induced autophagy resulting in enhanced cell survival remains currently unclear. One possibility would be that, similar to its role in starvation, autophagy may compensate for the loss of extrinsic signals that normally occur through integrins, promoting nutrient and energy metabolism. Mechanistically, autophagy is induced via persistent activation of AMPK and eukaryotic initiation factor-2 $\alpha$, both being inhibitors of mTOR [33].

Recently a new hypothesis has been proposed to resolve the apparent autophagy paradox in cancer: the "autophagic tumor stroma model of cancer cell metabolism," in which cancer cells used ROS to signal stromal cells to undergo autophagy, fueling them with nutrients [36]. 
Autophagy in the tumor stroma thus serves as a "battery" for energy transfer, in the form of recycled chemical building blocks, as well as lactate, to the highly proliferative cancer cells. To what extent this process really participates in tumor growth still needs to be evaluated.

\section{Role of autophagy in regulating anticancer agent-induced cell death}

\subsection{Balance between apoptosis and autophagy for inducing cell death}

In their revised version of the hallmarks of cancer, Hanahan and Weinberg added other types of cell death beyond the previously described apoptosis. In this regard, autophagy as well as necrosis are seen as contributing to and/or counteracting drug-induced apoptosis and cell death [37]. Complex crosstalk between apoptosis and autophagy has been unraveled. There is substantial evidence indicating that suppression of apoptosis induces autophagy, while autophagy inhibition causes apoptosis $[38,39]$. On the other hand, sometimes autophagy and apoptosis are triggered by a common upstream signal, suggesting at least one shared molecular switch. Beclin-1 is certainly a major player in this interplay [40]. This dual exclusive or cooperative interplay is well illustrated when the response of cancer cells to chemotherapy is investigated. Indeed, according to the drug and the cancer cell type, there are as many examples of a lethal effect of autophagy induction as examples of its anti-apoptotic, hence pro-survival, influence.

Few reports address the mechanisms by which chemotherapeutic agents trigger autophagy. These mechanisms may differ according to the type of drugs used, such as DNA-damaging agents, microtubule interfering molecules, kinase inhibitors, etc. One common pathway is the activation of $\mathrm{p} 53$; $\mathrm{p} 53$ then transcriptionally increases the expression of proteins involved in positively regulating the autophagy pathway. This is the case for AMPK, DAPK1 (Deathassociated protein kinase 1), TSC2 (tuberous sclerosis protein), ULK1/2, and sestrin 1/2 [41]. Other pathways involve activation of JNK, which induces Beclin-1 release from its inhibitory 
interaction with Bcl-2 at the level of the ER, through phosphorylation of the latter; increased Beclin-1 expression; increased level of VMP1 (vacuole membrane protein 1), which is a protein that interacts with Beclin-1 to regulate the Vps34 lipid kinase activity; inhibition of class I phosphatidyl inositol 3-kinases, which in turn inhibit mTOR; and activation of class III phosphatidyl inositol 3-kinases such as Vps34. The extent of their implications in different conditions and/or according to the cell type, their putative cooperation and the way they are actually initiated still need to be clarified. What also needs to be addressed is the question of whether the final outcome, death or survival, is influenced by the pathway through which autophagy is induced.

\subsection{Death inducing contribution of autophagy}

Various anticancer chemotherapies have been shown to induce autophagy, which in cooperation with apoptosis participates in the induction of cell death. In some cases, intact autophagy machinery is even required to induce cell death. Such a death-promoting effect has been described for a large variety of drugs in different cancer cell types. The first examples are for DNA-damaging agents in cell models in which autophagy is inhibited either by pharmacological inhibitors like 3-methyladenine or by the use of siRNA targeting Beclin-1, Atg5 or Atg7: hepatoma cells [42] or cervical carcinoma cells [43] exposed to etoposide, papillary thyroid cancer cells [44] or different sarcoma cell lines [45] incubated with doxorubin, cervical cancer SiHa cells exposed to carboplatin [46] or pancreatic cancer cells treated with gemcitabine [47]. Autophagy also contributes to cell death induced by microtubule targeting agents like paclitaxel $[48,49]$ as well as by the new "smart" drugs. The cytotoxicity induced by imatinib, an inhibitor of the tyrosine kinase activity of growth factor receptors, is decreased if autophagy is inhibited in human early stage malignant glioma cells [50]. Autophagic cell death is also induced in different cancer cell lines by HDAC (histone deacetylase) inhibitors [51]. Moreover, cell death is achieved by activating the autophagy 
pathway in cells that respond by weak apoptosis to cetuximab, a monoclonal antibody targeting the EGF receptor [52]. These different observations show that autophagy takes part in cell death induction in apoptosis competent cells while it becomes the major deathinducing pathway in apoptosis deficient cells.

Tumor hypoxia has been demonstrated to affect treatment outcome both in vitro and in vivo $[53,54]$. Several mechanisms explain this resistance; the main one is suppression of apoptosis, primarily due to the activation of the transcription factor HIF-1 (hypoxia-inducible factor-1) [55]. However, since more and more reports showed that autophagy participates in chemotherapeutic agent-induced cell death, the influence of hypoxia on autophagy in cells exposed to anticancer drugs has begun to be investigated as well. Two different effects have been shown: either hypoxia modifies the cytotoxic consequences of autophagy activation towards a pro-survival influence, as observed in HepG2 cells exposed to etoposide [42], or hypoxia itself induces autophagy, without being triggered by the drug, and this autophagy process is coupled with the blockage of apoptosis, thus preventing cell death. This has been observed in vitro in hepatocellular carcinoma cells [56] and in HeLa cells [57] as well as in vivo in murine models of head and neck squamous cell carcinomas [58]. The severity and/or the duration of hypoxia may tilt the balance toward one or the other, as already observed for apoptosis [59].

\subsection{Cytoprotective effect of autophagy}

Autophagy enables cancer cells to survive the harsh conditions of their microenvironment, while also enabling them to sustain chemotherapy thus conferring resistance. High level of autophagy detected in cells exposed to anticancer agents signifies an adaptive response [60]. This has been demonstrated by showing that autophagy inhibition synergizes with chemotherapeutic agents to more efficiently kill cancer cells in numerous cancer cell types 
exposed to various drugs. The reasons why, in some cases, autophagy participates to cell death while in others, it prevents it, are not understood, especially since both effects can be observed within the same anticancer molecule. Examples for a key role of autophagy in chemoresistance are numerous when DNA damaging agents are used: camptothecin in breast cancer cells [61]; cisplatin in esophageal squamous cell carcinoma cells [62], in metastatic skin carcinomas [63] and in lung adenocarcinoma cells [64]; and 5-fluorouracil in colon cancer cells [65] and in esophageal cancer cells [66]. Similar observations were obtained with the new generation drugs: proteasome inhibitors [67, 68], Src kinase inhibitor [69] and antiHER2 monoclonal antibody [70] are such examples.

The mechanism by which autophagy inhibition relieves resistance is often due to a shift toward apoptotic cell death. It has to be mentioned that cell crosstalk initiated by a dying cell induces autophagy in adjacent cells that renders them resistant to therapy. Dying cells release damage-associated molecular pattern molecules (DAMP), among which is HMGB1 (highmobility group box 1). This protein interacts with the surface of other cells via the RAGE receptor (Receptor for Advanced Glycation Endproducts) and induces autophagy and drug resistance (Figure 1). This dialogue has been demonstrated in leukemia cells [71, 72]. Whether such a process occurs in other types of cancer remains to be determined.

\section{$\underline{4 .}$ Targeting autophagy as a new anticancer therapeutic approach}

\subsection{To provoke cell death}

As described above, half of the studies show that autophagy is required for the efficient killing of tumor cells when treated with anticancer therapies. In line with these observations, researchers are working to design new drugs that would induce autophagy by themselves, and hence eliminate cancer cells [73]. Among the potential targets in autophagy, the Akt-mTOR pathway is the most investigated one. Indeed, proteins Akt, PTEN (Phosphatase and TENsin 
homolog) and mTOR, as well as some of the targets of the mTOR kinase, are often overexpressed or mutated in cancer. This pathway regulates numerous survival and proliferation networks in the cell; therefore, its inhibition not only activates autophagy but also cell cycle arrest and/or apoptosis [74]. Specific mTOR inhibitors have been developed and validated, and two of them (Everolimus and Temsirolimus) are now approved for the treatment of renal cell carcinoma and mantle cell lymphoma [75]. Everolimus indeed induces massive autophagy in vivo, with reduced tumoral mass, for example in leukemia [76], in advanced pancreatic tumors [77] and in many other tumors [78]. Concomitant combinations of etoposide, cisplatin or doxorubicin with everolimus produced cooperative antitumor effects, in some cases producing regressions without clinically significant increases in toxicity [79]. One mechanism responsible for this synergy is the activation of p53 by the DNA damaging agent. p53 then transactivates several genes whose products activate autophagy, such as AMPK, ULKs, DAPK1 and TSC2 (Figure 2).

Giaccia et al chose another approach, aiming to selectively kill renal clear carcinoma cells, and identified a molecule, STF-62247, that strongly induced autophagy, probably by disturbing protein trafficking between endoplasmic reticulum and Golgi [80]. Blocking autophagy using Atg5 or Atg7 siRNA prevents STF-62247-induced cell death, indicating that autophagy actually functions as a programmed cell death process in these cells.

Other drugs have also been shown to enhance autophagy, amongst other effects, all of which might participate in killing cancer cells. They are especially useful in the treatment of apoptosis-resistant cancer cells, for which alternate routes of cell killing must be found [81]. As for inducing apoptosis, modulation of some of the Bcl-2 family members also leads to autophagy-dependent cell death. This is notably the case for BH3 mimetics like gossypol that targets Bcl-2, thus allowing Beclin-1 to be released to initiate autophagosome formation [82] (Figure 3). Another example of molecule targeting anti-aptoptotic Bcl-2 family members is 
Obatoclax, which induces cell death on its own, but also potentiates the effects of other anticancer molecules such as the dual EGFR/HER2 inhibitor lapatinib [83] or HDAC inhibitors [84]. Some of these drugs aimed at elevating autophagy to eradicate cancer cells are currently being tested in clinical trials [73].

\subsection{To improve chemotherapeutic treatments}

Since high level of autophagy observed in tumor cells following anticancer treatment is thought to represent a protective response, therapeutic targeting of autophagosome formation/fusion might represent a novel molecular avenue to reduce the emergence of chemoresistance $[14,85]$. The proof of concept for autophagy inhibition as an adjuvant therapy is demonstrated by the use of chloroquine, a well-known anti-malarial agent, that inhibits lysosomal acidification and blocks the terminal stage of autophagy [86]. Chloroquine has indeed been shown to potentiate the anticancer effects of different drugs both in vitro and in vivo. It is the case for 5-fluorouracil in colon cancer cells [87], in a Myc-induced lymphoma mouse model treated with alkylating agents [88], in mouse models of prostate cancer treated with Src kinase inhibitor [69], or for imatinib-refractory chronic myeloid leukemia cells in combination with the HDAC inhibitor SAHA (suberoylanilide hydroxamic acid) [89]. Current phase I/II clinical trials are underway for evaluating the potential benefit of chloroquine in combination with conventional therapy for a variety of malignancies [73]. Despite the wide use of chloroquine in malaria prevention, some side effects have been reported. They include gastrointestinal problems, stomach ache, itch, headache, nightmares, blurred vision and retinopathy. In overdose, it becomes rapidly toxic. These side effects will have to be addressed if chloroquine is further developed for cancer treatment.

Other molecules display similar effects. 3-methyladenine was shown to enhance cell death induced by 5-fluorouracil in colorectal cancer cell lines [90], cytotoxicity induced by the 
tyrosine kinase inhibitor imatinib in glioma cell lines [91], as well as in chronic myeloid leukemia cells [89]. Schnekenburger et al have recently shown that the DNA demethylating agent, 2'-deoxy-5-azacytidine, induces autophagy that sensitizes chronic myeloid leukemia cells to conventional treatment [92].

However, it must be remembered that the anticancer effect of these different molecules might not be solely due to their inhibition of autophagy. New studies are needed to develop more specific inhibitors of this process. Targeting ULK1, Beclin-1 or Atg proteins are promising alternative routes.

\section{$\underline{\text { 5. Conclusion }}$}

The involvement of autophagy in chemotherapeutic agent-induced cell death is very complex. On one hand, autophagy may protect from apoptosis and hence, autophagy inhibitors have potential use as drugs to overcome anticancer therapy resistance. On the other hand, this process participates in cell death in certain circumstances. In that case, its induction may help to eradicate malignant cells. In order to reach clinical application, we must first better understand the factors that influence the effects of autophagy on cell death. Direct crosstalk between apoptosis and autophagy has been evidenced, and some of the mechanisms involved are aimed at reinforcing cell death $[93,94]$. A second issue to unravel would be to investigate whether the intensity and/or the speed of the autophagic process would determine the fate of the cell: severe and/or rapid autophagy might lead to cell death while mild and/or slow autophagy may favor cell survival. These different issues are summarized in Figure 4. The role of selectively targeted autophagy is another avenue of research. Indeed, as mentioned previously, hypoxia is known to trigger autophagy that actually thwarts cell death. Previous investigations demonstrated that selective autophagy for mitochondria - mitophagy prevents accumulation of damaged organelles that are sources of ROS. Determining whether 
this is also true for circumstances other than hypoxia and identifying the molecular mechanisms responsible for orientating autophagy to specific organelles would help to clarify the dual role of autophagy in regulating cell death.

Finally, the last step of autophagy involves autophagosome fusion with a lysosome. During the last decade, it was shown that destabilization of the lysosomal membrane and the partial release of lysosomal content into the cytosol can initiate and/or participate in apoptosis initiation. Despite being switched on, autophagy final step may be halted in such a situation. In this case, the cell has no choice but to die. On the other hand, with intact lysosomes, the final outcome could be survival. This hypothesis also needs to be experimentally tested.

Dysregulated autophagy is a hallmark of cancer cells; the challenge now is to decipher how to manipulate it for developing better therapeutic approaches for cancer patients.

\section{$\underline{\text { Acknowledgments }}$}

Annick Notte is a Research Fellow at FNRS (Fonds de la Recherche Scientifique, Belgium) and Lionel Leclere is a recipient of a FRIA grant (Fonds de la Recherche Scientifique, Belgium). This article presents results of the Belgian Program on Interuniversity Poles of Attraction initiated by the Belgian State, Prime Minister's Office, Science Policy Programming. The responsibility is assumed by its authors. 


\section{$\underline{\text { References }}$}

[1] Chabner BA and Roberts TG, Jr. Timeline: Chemotherapy and the war on cancer Nat Rev Cancer 2005; 5:65-72.

[2] DeVita VT, Jr. and Chu E. A history of cancer chemotherapy Cancer Res 2008; 68:864353.

[3] Pavet V, Portal MM, Moulin JC, Herbrecht R and Gronemeyer H. Towards novel paradigms for cancer therapy Oncogene 2011; 30:1-20.

[4] Ricci MS and Zong WX. Chemotherapeutic approaches for targeting cell death pathways Oncologist 2006; 11:342-57.

[5] Portugal J, Bataller M and Mansilla S. Cell death pathways in response to antitumor therapy Tumori 2009; 95:409-21.

[6] Al-Ejeh F, Kumar R, Wiegmans A, Lakhani SR, Brown MP and Khanna KK. Harnessing the complexity of DNA-damage response pathways to improve cancer treatment outcomes Oncogene 2010; 29:6085-98.

[7] Levine B and Yuan J. Autophagy in cell death: an innocent convict? J Clin Invest 2005; 115:2679-88.

[8] He C and Klionsky DJ. Regulation mechanisms and signaling pathways of autophagy Annu Rev Genet 2009; 43:67-93.

[9] Glick D, Barth S and Macleod KF. Autophagy: cellular and molecular mechanisms J Pathol 2010; 221:3-12.

[10] Yang Z and Klionsky DJ. An overview of the molecular mechanism of autophagy Curr Top Microbiol Immunol 2009; 335:1-32.

[11] Sinha S and Levine B. The autophagy effector Beclin 1: a novel BH3-only protein Oncogene 2008; 27 Suppl 1:S137-48. 
[12] Funderburk SF, Wang QJ and Yue Z. The Beclin 1-VPS34 complex--at the crossroads of autophagy and beyond Trends Cell Biol 2010; 20:355-62.

[13] Mathew R, Karantza-Wadsworth V and White E. Role of autophagy in cancer Nat Rev Cancer 2007; 7:961-7.

[14] Chen S, Rehman SK, Zhang W, Wen A, Yao L and Zhang J. Autophagy is a therapeutic target in anticancer drug resistance Biochim Biophys Acta 2010; 1806:220-9.

[15] Chen N and Debnath J. Autophagy and tumorigenesis FEBS Lett 2010; 584:1427-35.

[16] Koukourakis MI, Giatromanolaki A, Sivridis E, Pitiakoudis M, Gatter KC and Harris AL. Beclin 1 over- and underexpression in colorectal cancer: distinct patterns relate to prognosis and tumour hypoxia Br J Cancer 2010; 103:1209-14.

[17] Yue Z, Jin S, Yang C, Levine AJ and Heintz N. Beclin 1, an autophagy gene essential for early embryonic development, is a haploinsufficient tumor suppressor Proc Natl Acad Sci U S A $2003 ; 100: 15077-82$.

[18] Yoo BH, Wu X, Li Y, Haniff M, Sasazuki T, Shirasawa S, Eskelinen EL and Rosen KV. Oncogenic ras-induced down-regulation of autophagy mediator Beclin-1 is required for malignant transformation of intestinal epithelial cells J Biol Chem 2010; 285:5438-49.

[19] Liang XH, Jackson S, Seaman M, Brown K, Kempkes B, Hibshoosh H and Levine B. Induction of autophagy and inhibition of tumorigenesis by beclin 1 Nature 1999; 402:672-6.

[20] Miracco C, Cevenini G, Franchi A, Luzi P, Cosci E, Mourmouras V, Monciatti I, Mannucci S, Biagioli M, Toscano M, Moretti D, Lio R and Massi D. Beclin 1 and LC3 autophagic gene expression in cutaneous melanocytic lesions Hum Pathol 2010; 41:503-12. [21] Li Z, Chen B, Wu Y, Jin F, Xia Y and Liu X. Genetic and epigenetic silencing of the beclin 1 gene in sporadic breast tumors BMC Cancer 2010; 10:98. 
[22] Huang X, Bai HM, Chen L, Li B and Lu YC. Reduced expression of LC3B-II and Beclin 1 in glioblastoma multiforme indicates a down-regulated autophagic capacity that relates to the progression of astrocytic tumors J Clin Neurosci 2010; 17:1515-9.

[23] Iqbal J, Kucuk C, Deleeuw RJ, Srivastava G, Tam W, Geng H, Klinkebiel D, Christman JK, Patel K, Cao K, Shen L, Dybkaer K, Tsui IF, Ali H, Shimizu N, Au WY, Lam WL and Chan WC. Genomic analyses reveal global functional alterations that promote tumor growth and novel tumor suppressor genes in natural killer-cell malignancies Leukemia 2009; 23:1139-51.

[24] Liang C, Feng P, Ku B, Dotan I, Canaani D, Oh BH and Jung JU. Autophagic and tumour suppressor activity of a novel Beclin1-binding protein UVRAG Nat Cell Biol 2006; 8:688-99.

[25] Kim MS, Jeong EG, Ahn CH, Kim SS, Lee SH and Yoo NJ. Frameshift mutation of UVRAG, an autophagy-related gene, in gastric carcinomas with microsatellite instability Hum Pathol 2008; 39:1059-63.

[26] Marino G, Salvador-Montoliu N, Fueyo A, Knecht E, Mizushima N and Lopez-Otin C. Tissue-specific autophagy alterations and increased tumorigenesis in mice deficient in Atg4C/autophagin-3 J Biol Chem 2007; 282:18573-83.

[27] Coppola D, Khalil F, Eschrich SA, Boulware D, Yeatman T and Wang HG. Downregulation of Bax-interacting factor-1 in colorectal adenocarcinoma Cancer 2008; 113:266570.

[28] Hardt M, Chantaravisoot N and Tamanoi F. Activating mutations of TOR (target of rapamycin) Genes Cells 2011; 16:141-51.

[29] Mathew R, Kongara S, Beaudoin B, Karp CM, Bray K, Degenhardt K, Chen G, Jin S and White E. Autophagy suppresses tumor progression by limiting chromosomal instability Genes Dev 2007; 21:1367-81. 
[30] Mathew R, Karp CM, Beaudoin B, Vuong N, Chen G, Chen HY, Bray K, Reddy A, Bhanot G, Gelinas C, Dipaola RS, Karantza-Wadsworth V and White E. Autophagy suppresses tumorigenesis through elimination of p62 Cell 2009; 137:1062-75.

[31] Degenhardt K, Mathew R, Beaudoin B, Bray K, Anderson D, Chen G, Mukherjee C, Shi Y, Gelinas C, Fan Y, Nelson DA, Jin S and White E. Autophagy promotes tumor cell survival and restricts necrosis, inflammation, and tumorigenesis Cancer Cell 2006; 10:51-64.

[32] Kenific CM, Thorburn A and Debnath J. Autophagy and metastasis: another doubleedged sword Curr Opin Cell Biol 2010; 22:241-5.

[33] Horbinski C, Mojesky C and Kyprianou N. Live free or die: tales of homeless (cells) in cancer Am J Pathol 2010; 177:1044-52.

[34] Fung C, Lock R, Gao S, Salas E and Debnath J. Induction of autophagy during extracellular matrix detachment promotes cell survival Mol Biol Cell 2008; 19:797-806.

[35] Giatromanolaki A, Koukourakis MI, Harris AL, Polychronidis A, Gatter KC and Sivridis E. Prognostic relevance of light chain 3 (LC3A) autophagy patterns in colorectal adenocarcinomas J Clin Pathol 2010; 63:867-72.

[36] Martinez-Outschoorn UE, Whitaker-Menezes D, Pavlides S, Chiavarina B, Bonuccelli G, Casey T, Tsirigos A, Migneco G, Witkiewicz A, Balliet R, Mercier I, Wang C, Flomenberg N, Howell A, Lin Z, Caro J, Pestell RG, Sotgia F and Lisanti MP. The autophagic tumor stroma model of cancer or "battery-operated tumor growth": A simple solution to the autophagy paradox Cell Cycle 2010; 9:4297-306.

[37] Hanahan D and Weinberg RA. Hallmarks of cancer: the next generation Cell 2011; 144:646-74.

[38] Maiuri MC, Zalckvar E, Kimchi A and Kroemer G. Self-eating and self-killing: crosstalk between autophagy and apoptosis Nat Rev Mol Cell Biol 2007; 8:741-52. 
[39] Platini F, Perez-Tomas R, Ambrosio S and Tessitore L. Understanding autophagy in cell death control Curr Pharm Des 2010; 16:101-13.

[40] Kang R, Zeh HJ, Lotze MT and Tang D. The Beclin 1 network regulates autophagy and apoptosis Cell Death Differ 2011; 18:571-80.

[41] Feng Z. p53 regulation of the IGF-1/AKT/mTOR pathways and the endosomal compartment Cold Spring Harb Perspect Biol 2010; 2:a001057.

[42] Cosse JP, Rommelaere G, Ninane N, Arnould T and Michiels C. BNIP3 protects HepG2 cells against etoposide-induced cell death under hypoxia by an autophagy-independent pathway Biochem Pharmacol 2010; 80:1160-9.

[43] Lee SB, Tong SY, Kim JJ, Um SJ and Park JS. Caspase-independent autophagic cytotoxicity in etoposide-treated CaSki cervical carcinoma cells DNA Cell Biol 2007; 26:71320.

[44] Lin CI, Whang EE, Donner DB, Du J, Lorch J, He F, Jiang X, Price BD, Moore FD, Jr. and Ruan DT. Autophagy induction with RAD001 enhances chemosensitivity and radiosensitivity through Met inhibition in papillary thyroid cancer Mol Cancer Res 2010; 8:1217-26.

[45] Lambert LA, Qiao N, Hunt KK, Lambert DH, Mills GB, Meijer L and Keyomarsi K. Autophagy: a novel mechanism of synergistic cytotoxicity between doxorubicin and roscovitine in a sarcoma model Cancer Res 2008; 68:7966-74.

[46] Sun Y, Zhang J and Peng ZL. Beclin1 induces autophagy and its potential contributions to sensitizes SiHa cells to carboplatin therapy Int J Gynecol Cancer 2009; 19:772-6.

[47] Mukubou H, Tsujimura T, Sasaki R and Ku Y. The role of autophagy in the treatment of pancreatic cancer with gemcitabine and ionizing radiation Int J Oncol 2010; 37:821-8. 
[48] Zou CF, Jia L, Jin H, Yao M, Zhao N, Huan J, Lu Z, Bast RC, Jr., Feng Y and Yu Y. Reexpression of ARHI (DIRAS3) induces autophagy in breast cancer cells and enhances the inhibitory effect of paclitaxel BMC Cancer 2011; 11:22.

[49] Eum KH and Lee M. Crosstalk between autophagy and apoptosis in the regulation of paclitaxel-induced cell death in v-Ha-ras-transformed fibroblasts Mol Cell Biochem 2011; 348:61-8.

[50] Shingu T, Fujiwara K, Bogler O, Akiyama Y, Moritake K, Shinojima N, Tamada Y, Yokoyama T and Kondo S. Stage-specific effect of inhibition of autophagy on chemotherapyinduced cytotoxicity Autophagy 2009; 5:537-9.

[51] Yang PM and Chen CC. Life or death? Autophagy in anticancer therapies with statins and histone deacetylase inhibitors Autophagy 2011; 7:107-8.

[52] Li X, Lu Y, Pan T and Fan Z. Roles of autophagy in cetuximab-mediated cancer therapy against EGFR Autophagy 2010; 6:1066-77.

[53] Rohwer $\mathrm{N}$ and Cramer T. Hypoxia-mediated drug resistance: Novel insights on the functional interaction of HIFs and cell death pathways Drug Resist Updat 2011;

[54] Cosse JP and Michiels C. Tumour hypoxia affects the responsiveness of cancer cells to chemotherapy and promotes cancer progression Anticancer Agents Med Chem 2008; 8:790-7. [55] Sermeus A, Cosse JP, Crespin M, Mainfroid V, de Longueville F, Ninane N, Raes M, Remacle J and Michiels C. Hypoxia induces protection against etoposide-induced apoptosis: molecular profiling of changes in gene expression and transcription factor activity Mol Cancer 2008; 7:27.

[56] Song J, Qu Z, Guo X, Zhao Q, Zhao X, Gao L, Sun K, Shen F, Wu M and Wei L. Hypoxia-induced autophagy contributes to the chemoresistance of hepatocellular carcinoma cells Autophagy 2009; 5:1131-44. 
[57] Liu XW, Su Y, Zhu H, Cao J, Ding WJ, Zhao YC, He QJ and Yang B. HIF-1alphadependent autophagy protects HeLa cells from fenretinide (4-HPR)-induced apoptosis in hypoxia Pharmacol Res 2010; 62:416-25.

[58] Vigneswaran N, Wu J, Song A, Annapragada A and Zacharias W. Hypoxia-induced autophagic response is associated with aggressive phenotype and elevated incidence of metastasis in orthotopic immunocompetent murine models of head and neck squamous cell carcinomas (HNSCC) Exp Mol Pathol 2011; 90:215-25.

[59] Piret JP, Mottet D, Raes M and Michiels C. Is HIF-1alpha a pro- or an anti-apoptotic protein? Biochem Pharmacol 2002; 64:889-92.

[60] Kondo Y, Kanzawa T, Sawaya R and Kondo S. The role of autophagy in cancer development and response to therapy Nat Rev Cancer 2005; 5:726-34.

[61] Abedin MJ, Wang D, McDonnell MA, Lehmann U and Kelekar A. Autophagy delays apoptotic death in breast cancer cells following DNA damage Cell Death Differ 2007; 14:500-10.

[62] Liu D, Yang Y, Liu Q and Wang J. Inhibition of autophagy by 3-MA potentiates cisplatin-induced apoptosis in esophageal squamous cell carcinoma cells Med Oncol 2011; 28:105-11.

[63] Claerhout S, Verschooten L, Van Kelst S, De Vos R, Proby C, Agostinis P and Garmyn M. Concomitant inhibition of AKT and autophagy is required for efficient cisplatin-induced apoptosis of metastatic skin carcinoma Int J Cancer 2010; 127:2790-803.

[64] Ren JH, He WS, Nong L, Zhu QY, Hu K, Zhang RG, Huang LL, Zhu F and Wu G. Acquired cisplatin resistance in human lung adenocarcinoma cells is associated with enhanced autophagy Cancer Biother Radiopharm 2010; 25:75-80. 
[65] Li J, Hou N, Faried A, Tsutsumi S and Kuwano H. Inhibition of autophagy augments 5fluorouracil chemotherapy in human colon cancer in vitro and in vivo model Eur J Cancer $2010 ; 46: 1900-9$.

[66] O'Donovan TR, O'Sullivan GC and McKenna S. Induction of autophagy by drugresistant esophageal cancer cells promotes their survival and recovery following treatment with chemotherapeutics Autophagy 2011; 7:

[67] Zhu K, Dunner K, Jr. and McConkey DJ. Proteasome inhibitors activate autophagy as a cytoprotective response in human prostate cancer cells Oncogene 2010; 29:451-62.

[68] Wu WK, Sakamoto KM, Milani M, Aldana-Masankgay G, Fan D, Wu K, Lee CW, Cho $\mathrm{CH}, \mathrm{Yu}$ J and Sung JJ. Macroautophagy modulates cellular response to proteasome inhibitors in cancer therapy Drug Resist Updat 2010; 13:87-92.

[69] Wu Z, Chang PC, Yang JC, Chu CY, Wang LY, Chen NT, Ma AH, Desai SJ, Lo SH, Evans CP, Lam KS and Kung HJ. Autophagy Blockade Sensitizes Prostate Cancer Cells towards Src Family Kinase Inhibitors Genes Cancer 2010; 1:40-9.

[70] Vazquez-Martin A, Oliveras-Ferraros C and Menendez JA. Autophagy facilitates the development of breast cancer resistance to the anti-HER2 monoclonal antibody trastuzumab PLoS One 2009; 4:e6251.

[71] Liu L, Yang M, Kang R, Wang Z, Zhao Y, Yu Y, Xie M, Yin X, Livesey KM, Loze MT, Tang D and Cao L. DAMP-mediated autophagy contributes to drug resistance Autophagy $2011 ; 7: 112-4$

[72] Liu L, Yang M, Kang R, Wang Z, Zhao Y, Yu Y, Xie M, Yin X, Livesey KM, Lotze MT, Tang D and Cao L. HMGB1-induced autophagy promotes chemotherapy resistance in leukemia cells Leukemia 2011;25:23-31.

[73] Levy JM and Thorburn A. Targeting autophagy during cancer therapy to improve clinical outcomes Pharmacol Ther 2011; 
[74] Easton JB and Houghton PJ. mTOR and cancer therapy Oncogene 2006; 25:6436-46.

[75] Ciuffreda L, Di Sanza C, Incani UC and Milella M. The mTOR pathway: a new target in cancer therapy Curr Cancer Drug Targets 2010; 10:484-95.

[76] Crazzolara R, Bradstock KF and Bendall LJ. RAD001 (Everolimus) induces autophagy in acute lymphoblastic leukemia Autophagy 2009; 5:727-8.

[77] Yao JC, Lombard-Bohas C, Baudin E, Kvols LK, Rougier P, Ruszniewski P, Hoosen S, St Peter J, Haas T, Lebwohl D, Van Cutsem E, Kulke MH, Hobday TJ, O'Dorisio TM, Shah MH, Cadiot G, Luppi G, Posey JA and Wiedenmann B. Daily oral everolimus activity in patients with metastatic pancreatic neuroendocrine tumors after failure of cytotoxic chemotherapy: a phase II trial J Clin Oncol 2010; 28:69-76.

[78] Dancey J. mTOR signaling and drug development in cancer Nat Rev Clin Oncol 2010; 7:209-19.

[79] O'Reilly T, McSheehy PM, Wartmann M, Lassota P, Brandt R and Lane HA. Evaluation of the mTOR inhibitor, everolimus, in combination with cytotoxic antitumor agents using human tumor models in vitro and in vivo Anticancer Drugs 2011; 22:58-78.

[80] Turcotte S, Chan DA, Sutphin PD, Hay MP, Denny WA and Giaccia AJ. A molecule targeting VHL-deficient renal cell carcinoma that induces autophagy Cancer Cell 2008; 14:90-102.

[81] Schleicher SM, Moretti L, Varki V and Lu B. Progress in the unraveling of the endoplasmic reticulum stress/autophagy pathway and cancer: implications for future therapeutic approaches Drug Resist Updat 2010; 13:79-86.

[82] Voss V, Senft C, Lang V, Ronellenfitsch MW, Steinbach JP, Seifert V and Kogel D. The pan-Bcl-2 inhibitor (-)-gossypol triggers autophagic cell death in malignant glioma Mol Cancer Res 2010; 8:1002-16. 
[83] Martin AP, Mitchell C, Rahmani M, Nephew KP, Grant S and Dent P. Inhibition of MCL-1 enhances lapatinib toxicity and overcomes lapatinib resistance via BAK-dependent autophagy Cancer Biol Ther 2009; 8:2084-96.

[84] Wei Y, Kadia T, Tong W, Zhang M, Jia Y, Yang H, Hu Y, Viallet J, O'Brien S and Garcia-Manero G. The combination of a histone deacetylase inhibitor with the BH3-mimetic GX15-070 has synergistic antileukemia activity by activating both apoptosis and autophagy Autophagy 2010; 6:976-8.

[85] Livesey KM, Tang D, Zeh HJ and Lotze MT. Autophagy inhibition in combination cancer treatment Curr Opin Investig Drugs 2009; 10:1269-79.

[86] Amaravadi RK, Lippincott-Schwartz J, Yin XM, Weiss WA, Takebe N, Timmer W, DiPaola RS, Lotze MT and White E. Principles and current strategies for targeting autophagy for cancer treatment Clin Cancer Res 2011; 17:654-66.

[87] Sasaki K, Tsuno NH, Sunami E, Tsurita G, Kawai K, Okaji Y, Nishikawa T, Shuno Y, Hongo K, Hiyoshi M, Kaneko M, Kitayama J, Takahashi K and Nagawa H. Chloroquine potentiates the anti-cancer effect of 5-fluorouracil on colon cancer cells BMC Cancer 2010; $10: 370$.

[88] Amaravadi RK, Yu D, Lum JJ, Bui T, Christophorou MA, Evan GI, ThomasTikhonenko A and Thompson CB. Autophagy inhibition enhances therapy-induced apoptosis in a Myc-induced model of lymphoma J Clin Invest 2007; 117:326-36.

[89] Carew JS, Nawrocki ST, Kahue CN, Zhang H, Yang C, Chung L, Houghton JA, Huang P, Giles FJ and Cleveland JL. Targeting autophagy augments the anticancer activity of the histone deacetylase inhibitor SAHA to overcome Bcr-Abl-mediated drug resistance Blood $2007 ; 110: 313-22$.

[90] Bijnsdorp IV, Peters GJ, Temmink OH, Fukushima M and Kruyt FA. Differential activation of cell death and autophagy results in an increased cytotoxic potential for 
trifluorothymidine compared to 5-fluorouracil in colon cancer cells Int J Cancer 2010; 126:2457-68.

[91] Shingu T, Fujiwara K, Bogler O, Akiyama Y, Moritake K, Shinojima N, Tamada Y, Yokoyama T and Kondo S. Inhibition of autophagy at a late stage enhances imatinib-induced cytotoxicity in human malignant glioma cells Int J Cancer 2009; 124:1060-71.

[92] Schnekenburger M, Grandjenette C, Ghelfi J, Karius T, Foliguet B, Dicato M and Diederich M. Sustained exposure to the DNA demethylating agent, 2'-deoxy-5-azacytidine, leads to apoptotic cell death in chronic myeloid leukemia by promoting differentiation, senescence, and autophagy Biochem Pharmacol 2011; 81:364-78.

[93] Li H, Wang P, Sun Q, Ding WX, Yin XM, Sobol RW, Beer-Stolz D, Yu J and Zhang L. Following cytochrome c release, autophagy is inhibited during chemotherapy-induced apoptosis by caspase-8-mediated cleavage of Beclin-1 Cancer Res 2011;

[94] Giansanti V, Torriglia A and Scovassi AI. Conversation between apoptosis and autophagy: "Is it your turn or mine?" Apoptosis 2011; 16:321-33. 


\section{$\underline{\text { Figure legends }}$}

Figure 1: Schematic representation of the dialogue between dying cells and neighboring cells that are protected from anticancer agents. Dying cells release DAMP. DAMP, including is HMGB1, interacts with RAGE on the surface of adjacent cells, hence inhibiting mTOR and triggering autophagy that exerts a cytoprotective effect.

Figure 2: Schematic representation of the cell death-inducing effects of mTOR inhibitors. mTOR inhibitors such as temsinolimus and everolimus activate autophagy that participates in cell death. This synergizes with the effects of DNA damaging agents via the activation of $\mathrm{p} 53$. p53 transcriptionally increases the expression of several proteins known to induce autophagy such as AMPK, ULKs, DAPK-1 and TCS2.

Figure 3: Schematic representation of the cell death-inducing effects of BH3 mimetics. On one hand, $\mathrm{BH} 3$ mimetics releases pro-apoptotic proteins like Bax or Bak from their inhibitory interaction with the anti-apoptotic members of the Bcl-2 family, hence inducing apoptosis through cytochrome $\mathrm{c}$ release from the mitochondria and caspase activation. On the other hand, these molecules also liberate Beclin-1 from Bcl-2 localized on the ER. Freed beclin-1 then induces autophagy. Both apoptosis and autophagy take part in inducing cell death.

Figure 4: Schematic representation of the dual action of autophagy in regulating chemotherapeutic agent-induced cell death. On one hand, anticancer molecules induce apoptosis through the intrinsic pathway involving cytochrome $\mathrm{c}$ release from the mitochondria and caspase activation. A positive feedback loop involves caspase-dependent 
cleavage of Beclin-1; truncated Beclin-1 then relocates to mitochondria to enhance cytochrome c release. Apoptosis may also be triggered by the activation of calpain that cleaves to Atg5; truncated Atg5 then translocates to the mitochondria and interacts with Bcl$\mathrm{X}_{\mathrm{L}}$. Autophagy induction occurs via JNK activation that release Beclin-1 from Bcl-2 by phosphorylating the latter. Chemotherapeutic agents also trigger autophagy. Several mechanisms are involved. One pathway involves JNK that releases Beclin-1 from its inhibitory interaction with Bcl-2 at the level of the ER, via Bcl-2 phosphorylation. Whether autophagy is protective or cytotoxic may be due to its severity or duration. Mild and/or slow autophagy may enhance cell survival while more severe and/or rapid autophagy would take part in inducing to cell death.

tAtg5, truncated Atg5; tBeclin, truncated Beclin-1 


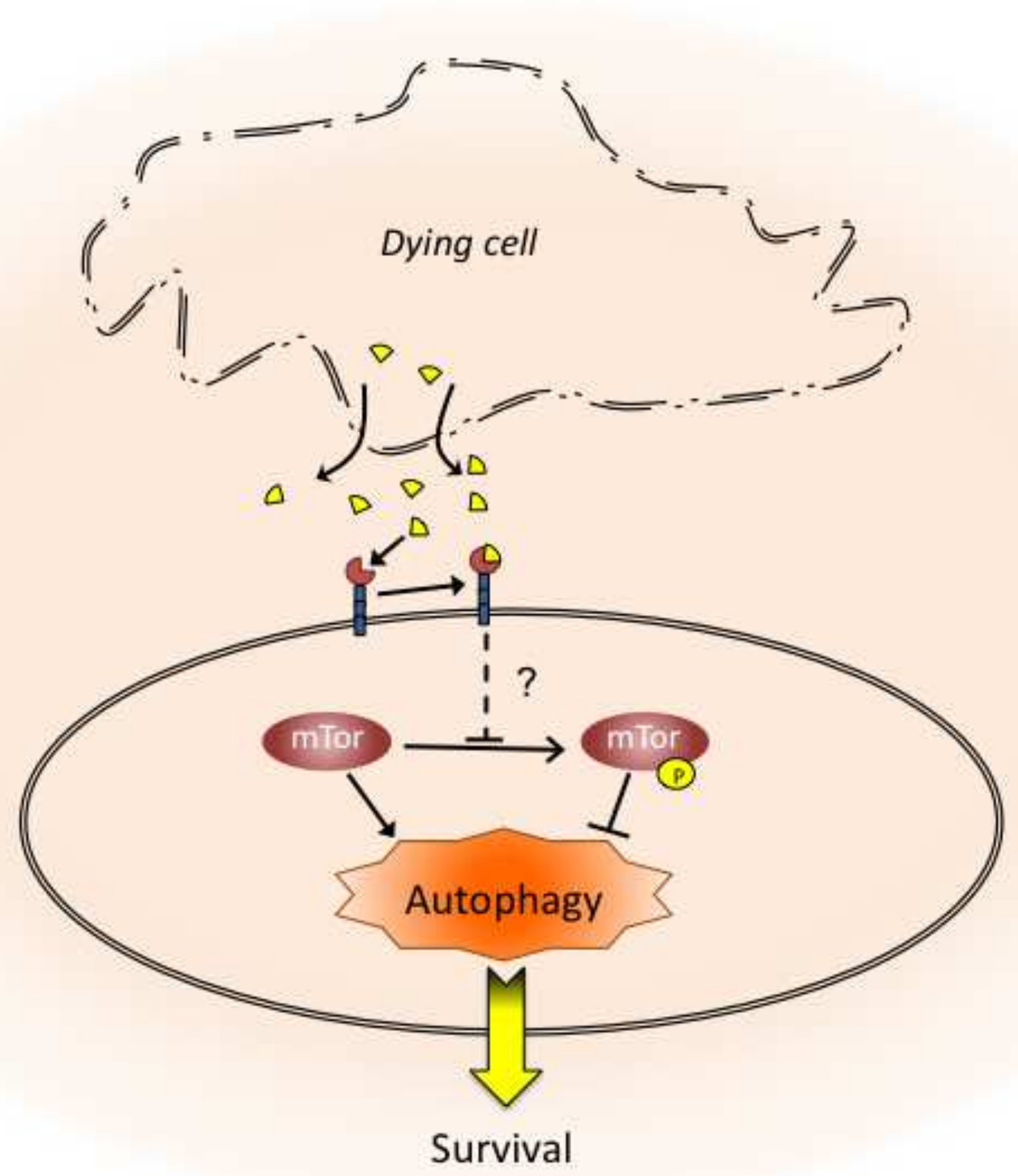

rage $2 y$ or 33

Figure 1

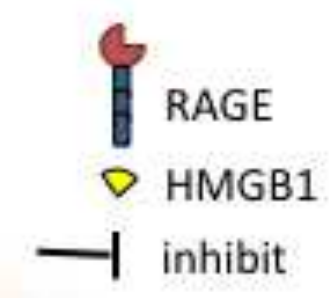




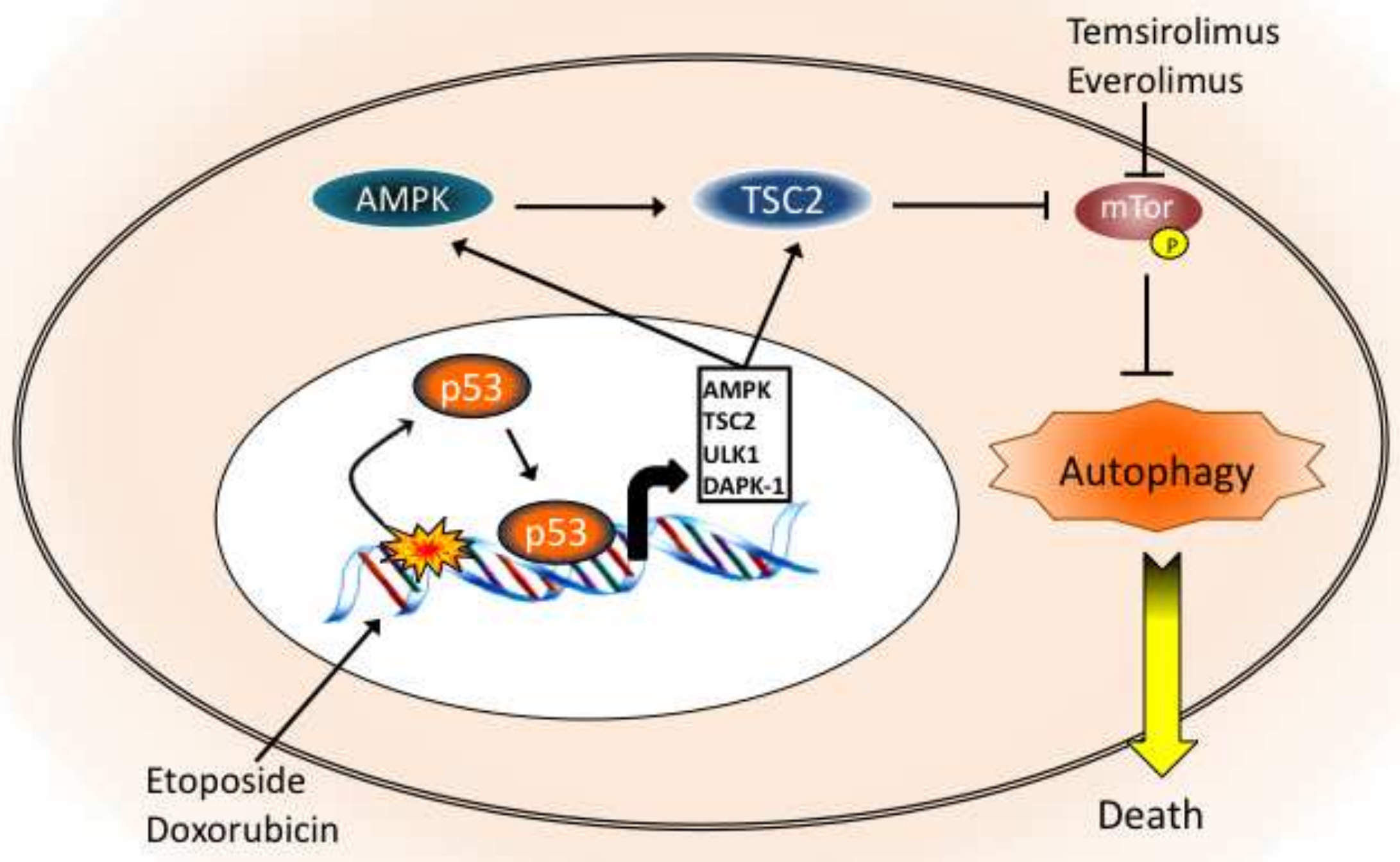

Figure 2 


\section{BH3 mimetics}
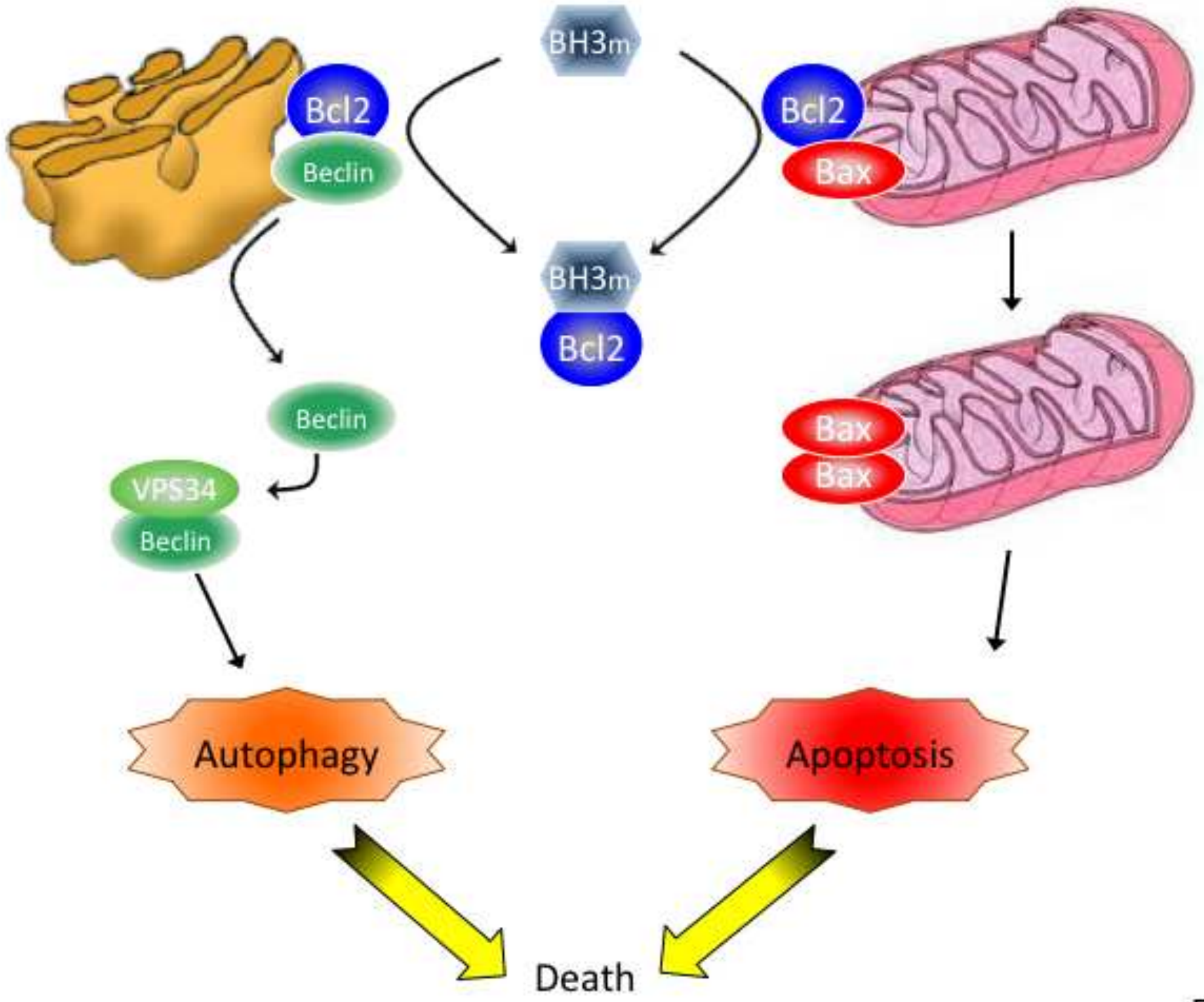

Figure 3

rage 31 оा 33 
Figure 4

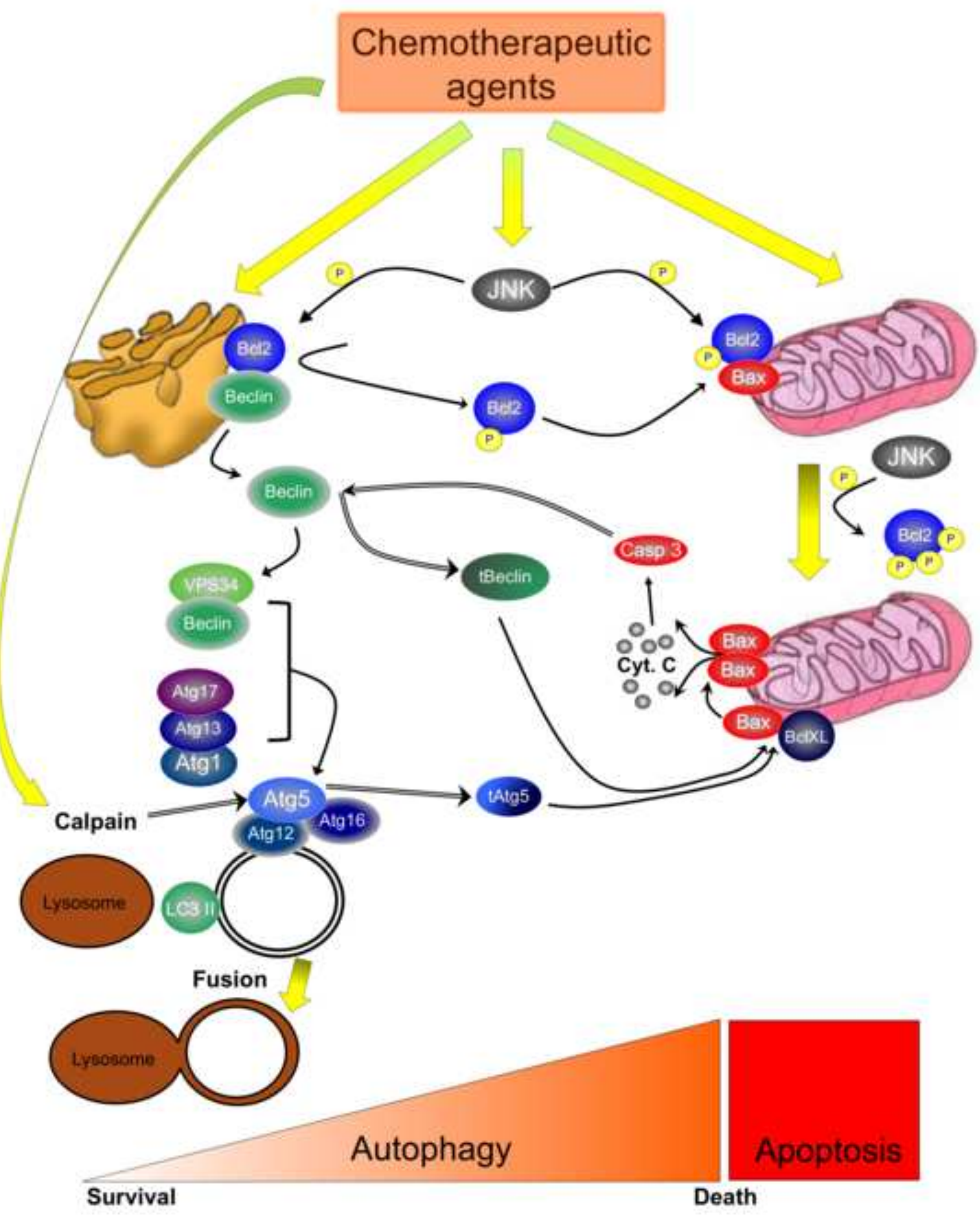




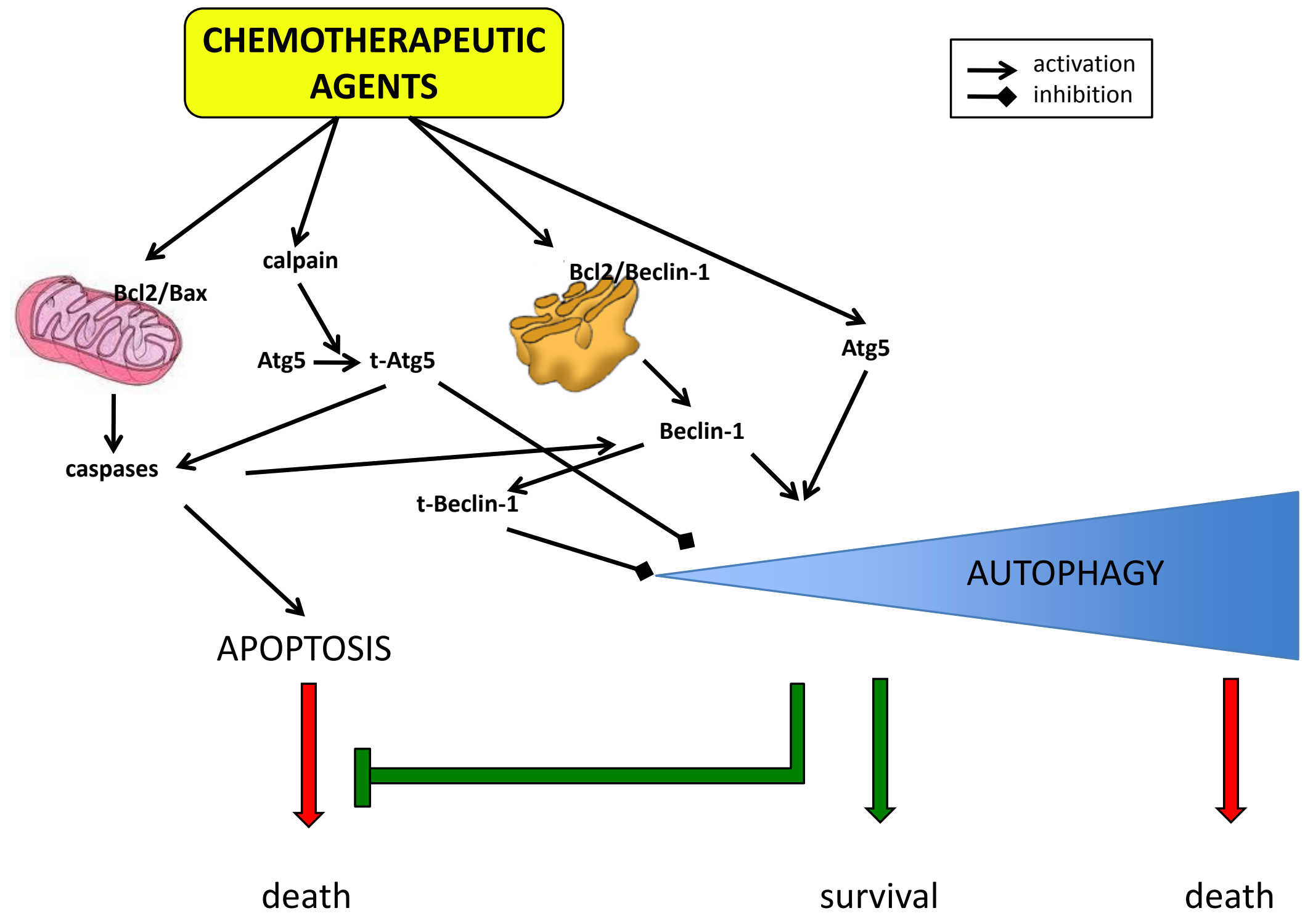

